\title{
(In)Formação musical: proximidades antropo comunicacionais epistemológicas sobre o Catolicismo e o Candomblé
}

\author{
Musical (In)Formation: anthropological communicative and epistemological \\ nearby about Catholicism and Candomble
}

\section{(In)Formación musical: enfoques antropológico comunicativo y epistemológico sobre el Catolicismo y el Candomblé}

\author{
Ana Maria Ferreira da Silval \\ Luciana Ferreira da Costa ${ }^{2}$ \\ Alan Curcino Pedreira da Silva ${ }^{3}$ \\ Maria de Fátima Nunes ${ }^{4}$
}

\section{Resumo}

$\mathrm{O}$ artigo analisa o fenômeno sócio religioso como (in)formacional sobre a experiência do homem com o sagrado por meio da música nos ritos antropo-comunicacionais de comunhão do Catolicismo e do Candomblé. A discussão sobre o tema é ancorado pelo diálogo transversal entre as áreas da Ciência da Informação, da Comunicação e das Ciências da Religião, utilizando-se de referências antropológicas e sociológicas. Apresenta definição de música, sua presença em lugares e meio de comunicação no cotidiano dos indivíduos, incluindo sua presença em rituais de exaltação a determinadas entidades no âmbito das religiões. Aborda como a música é enfocada no contexto do Catolicismo e do Candomblé como instrumento de celebração, de comunicação, de instrução, de educação de crenças e tradições religiosas. Conclui que o conhecimento acerca da música nos espaços sagrados precisa ser amplamente investigado e compreendido, sobretudo no que se refere à utilização e funções da música na experiência religiosa e na interação do ser humano com a música.

\begin{tabular}{|c|c|}
\hline \multirow{3}{*}{ 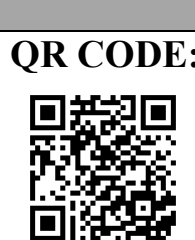 } & Acesse este artigo online \\
\hline & $\begin{array}{l}\text { Website: } \\
\text { http://www.revistas.ufg.br/index.php/ci }\end{array}$ \\
\hline & $\begin{array}{l}\text { DOI: } \\
\text { https://www.revistas.ufg.br/ci/article/vi } \\
\text { ew/38026/22231 }\end{array}$ \\
\hline
\end{tabular}

Palavras-chave: Comunicação. Informação musical. Religião. Catolicismo. Candomblé.

\footnotetext{
${ }^{1}$ Especialista em Ciências das Religiões e em Educação em Direitos Humanos, graduada em Pedagogia com habilitação em Supervisão Escolar na Universidade Federal da Paraíba (UFPB). Coordenadora do Programa Mais Educação do Governo Federal em conjunto com a Prefeitura Municipal de João Pessoa. Brasil, Paraíba, João Pessoa. E-mail: aninhamariafv@yahoo.com.br

${ }^{2}$ Doutoranda em História e Filosofia da Ciência com Especialidade em Museologia pela Universidade de Évora, Mestre em Ciência da Informação e Bacharela em Biblioteconomia pela Universidade Federal da Paraíba (UFPB). Professora do Departamento de Ciência da Informação da Universidade Federal da Paraíba (UFPB). Brasil, Paraíba, João Pessoa. E-mail: lucianna.costa@yahoo.com.br

3 Doutorando em Filosofia pelo Programa de Pós-Graduação Integrado de Doutorado em Filosofia das Universidades Federais da Paraíba, Pernambuco e Rio Grande do Norte (UFPB - UFPE - UFRN), mestre em Ciência da Informação pela Universidade Federal da Paraíba (UFPB) e Bacharel em Ciências Contábeis pela Universidade Federal da Bahia (UFBA). Professor da Universidade Federal de Alagoas (UFAL). Brasil, Alagoas, Penedo. E-mail: alancurcino@hotmail.com

${ }^{4}$ Doutora em História da Cultura Moderna Contemporânea pela Universidade de Évora, mestre em História Cultural e Política pela Faculdade de Ciências Sociais e Humanas da Universidade Nova de Lisboa e licenciada em História pela Faculdade de Letras da Universidade de Lisboa. Professora Catedrática da Universidade de Évora. Portugal, Évora. Email: mfn@uevora.pt
}

Comun. \& Inf., Goiânia, GO, v. 19, n. 2, p. 04-18, jul./dez. 2016. 


\begin{abstract}
The article analyzes the religious phenomenon as a partner (in)formational about man's experience with the sacred through music in anthropological-communicative communion rites of Catholicism and Candomblé. The discussion on the topic is anchored by cross dialogue between the areas of Information Science, Communication and Religious Studies, using anthropological and sociological references. Features music setting, its presence in places and means of communication in daily life, including their presence in exaltation rituals to certain entities within the religions. Discusses how music is analyzed in the context of Catholicism and Candomblé as a celebration instrument, communication, education, education of religious beliefs and traditions. Concludes that music knowledge in sacred spaces must be thoroughly investigated and understood, especially as regards the use and functions of music in religious experience and interaction of human beings with the music.
\end{abstract}

Keywords: Communication. Musical information. Religion. Catholicism. Candomble.

\title{
Resumen
}

El artículo analiza el fenómeno religioso como socio (in) formativo sobre la experiencia del hombre con lo sagrado a través de la música en los ritos de comunión antropológico-comunicativas del catolicismo y el Candomblé. La discusión sobre el tema está anclado por el diálogo intercultural entre las áreas de Ciencias de la Información, Comunicación y Estudios Religiosos, utilizando referencias antropológicas y sociológicas. Características Marco de la música, su presencia en los lugares y medios de comunicación en la vida cotidiana, incluyendo su presencia en los rituales exaltación a ciertas entidades dentro de las religiones. Explica cómo se analiza la música en el contexto del catolicismo y Candomblé como instrumento de celebración, la comunicación, la educación, la educación de las creencias y tradiciones religiosas. Concluye que el conocimiento de la música en los espacios sagrados debe ser investigado y comprendido a fondo, sobre todo en lo relativo al uso y funciones de la música en la experiencia religiosa y la interacción de los seres humanos con la música.

Palabras-clave: Comunicación. Información Musical. Religión. Catolicismo. Candomblé.

\section{INTRODUÇÃO}

música faz parte do cotidiano do ser humano e está presente nos mais
variados lugares (casa, escola, rua, loja, bar, consultório, etc.) e nos mais
variados meios de comunicação, como Internet, rádio, TV, smartphones, dentre outros (HUMMES, 2004; VIEIRA, 2012). A música é reconhecida como “indispensável para a promulgação apropriada das atividades que constituem uma sociedade; é um comportamento humano universal" (HUMMES, 2004, p. 19).

Certamente, inclui-se nos lugares descritos a presença da música nos rituais de exaltação no âmbito das religiões. O fato é que a música tem papel essencial na liturgia de todos os ritos antropocomunicacionais, inclusive tanto católicos quanto afro-brasileiros. Aliás, seu papel é considerado "mágico e simbólico".

Ao se refletir sobre a música, em qualquer que seja a religião, depara-se com o retrato desta religião e com o cenário de seus sistemas simbólicos de comunicação e informação.

Na perspectiva de Ferreira (2006), a música é um tipo de código comunicacional humano multicultural e global que mostra os fundamentos da religião na qual é empregada.

Comun. \& Inf., Goiânia, GO, v. 19, n. 2, p. 04-18, jul./dez. 2016. 
Música e religião tem sido tema de pesquisas. Um exemplo é a pesquisa de Oliveira (2014), desenvolvida no âmbito da Universidade Estadual Paulista Júlio de Mesquita Filho, que mapeou a maneira como diferentes pessoas, de diferentes idades e credos se relacionam com a música, sobretudo, a que se dá no contexto de funções litúrgicas islâmicas, judaicas e cristãs.

Outro exemplo é a pesquisa de Mendonça (2014), também da Universidade Estadual Paulista Júlio de Mesquita Filho, que se dedicou a observar o campo musical da Igreja Adventista do Sétimo Dia na transmissão de sua mensagem teológica.

Mais um exemplo é a pesquisa de Lôbo e Christian (2014), desenvolvida pela Universidade do Estado do Rio Grande do Norte, que se dedicou ao novo horizonte de propagação da mensagem religiosa através da música, assumindo novos contornos através dos meios massivos, com ênfase no rádio, levando simultaneamente fé e entretenimento.

Menciona-se, também, a pesquisa de Ferreira (2006) desenvolvida no âmbito do Programa de Pós-graduação em Ciências das Religiões na Universidade Federal da Paraíba, que realizou um estudo comparativo da música nos ritos das religiões Católica e do Candomblé.

No contexto formativo do ensino básico brasileiro, a (in)formação religiosa teve, desde o ano de 2006, sua importância reconhecida pela inserção obrigatória da disciplina Ensino Religioso no ensino nacional, conforme a Lei das Diretrizes e Bases da Educação:

Art. 33. O ensino religioso, de matrículas facultativas, é parte integrante da formação básica do cidadão e constitui disciplina dos horários normais das escolas públicas de ensino fundamental, assegurando o respeito à diversidade cultural religiosa do Brasil, vedadas quaisquer formas de proselitismo (BRASIL, 1996).

$\mathrm{Na}$ esfera internacional, as reflexões acerca da música como produto/sistema comunicacional de informação no âmbito da pós-graduação não é recente:

[...] no ano de 2007 a Universidad de San Pablo, em Madrid-Espanha, lançou o primeiro Curso de Mestrado em Comunicação e Informação Social e Religiosa, reconhecido pela Comunidade Europeia, enfocando justamente tal temática em seu projeto curricular, articulando profissionais tanto das Ciências das Religiões quanto das Ciências da Informação, como assim estas últimas são tratadas na Espanha, ao conhecimento e experiência das diversas políticas e culturas relacionadas à religião por meio dos diversos rituais, fontes e canais informacionais utilizados pela sociedade quando vivenciam o sagrado (ZENIT, 2009 apud COSTA; RAMALHO, 2010, p. 171).

Esse curso de mestrado da Universidad San Pablo é citado por Costa e Ramalho (2010) em pesquisa realizada no âmbito da Ciência da Informação e Comunicação com o aporte das Ciências das Religiões sobre práticas informacionais dos estudantes do Curso de Mestrado do Programa de Pós-Graduação em Ciências das Religiões da Universidade Federal da Paraíba

Comun. \& Inf., Goiânia, GO, v. 19, n. 2, p. 04-18, jul./dez. 2016. 
através do modelo de comportamento de busca e uso da informação desenvolvido por David Ellis.

Dessa forma, considerando o cenário exposto, apresenta-se aqui artigo que objetivou analisar o fenômeno sócio religioso como (in)formacional com foco sobre a experiência do homem com o sagrado por meio da música nos ritos antropo-comunicacionais de comunhão do Catolicismo e do Candomblé.

\section{A EXPERIÊNCIA (IN)FORMACIONAL DO SAGRADO}

O verbete "experiência" pode significar o ato ou efeito de experimentar(-se), experimentação, prática da vida, conhecimento que nos é transmitido pelos sentidos (FERREIRA, 2004).

A experiência do homem com o sagrado é tratada por Eliade (1992) como algo relacionado às ideias de ser, sentido e verdade, não necessariamente uma crença em Deus, deuses ou fantasmas, mas como uma consciência de mundo real, que leva o homem a aprender a diferença entre as revelações que se apresentam de modo satisfatório, poderoso e rico, das revelações caóticas e sem sentido.

Na perspectiva de Otto (1985) a experiência com o sagrado é vista como sendo o mysterium tremendum, ou uma vivência considerada fascinante diante do ser ou do objeto sagrado. Essa vivência ou sensação pode se concretizar e ser comunicada de diversos modos, representando êxtase, graça, transe, força, energia, etc., enquanto manifestações a partir do espiritual. A experiência com o sagrado, portanto, apresenta-se como uma realidade de ordem absolutamente diferente da realidade natural humana.

Traz-se à discussão o conceito de comunhão que significa o ato ou o efeito de comungar, comunicar e participar em comum de crenças, interesses, ideias, ou o conjunto daqueles que acreditam e partilham os mesmos ideais, crenças ou opiniões, podendo também direcionar ao termo de comunidade (FERREIRA, 2004). Consequentemente, no campo religioso, a comunhão expressaria, portanto, a religação com o sagrado, compreendida, ainda, como comunicação com o sagrado.

A comunhão é encarada pelo Catolicismo como um importante rito de comunicação sacramental pertencente à liturgia da igreja. Nesta religião, a comunhão é um dos sete sacramentos da Igreja Católica, juntamente com: batismo, crisma, matrimônio, sacramento da ordem, confissão e unção dos enfermos.

Comun. \& Inf., Goiânia, GO, v. 19, n. 2, p. 04-18, jul./dez. 2016. 
Ferreira (2004) ainda considera comunhão, quando relacionada à religião, a eucaristia ou à administração ou recepção da eucaristia, tratando-se da parte da liturgia da missa que sucede à liturgia eucarística. E, nessa perspectiva, a acepção da eucaristia consiste em:

[Do gr. eucharistía, pelo lat. eucharistia.] Substantivo feminino. Rel. 1. Um dos sete sacramentos da Igreja Católica, no qual, segundo a crença, Jesus Cristo se acha presente, sob as aparências do pão e do vinho, com seu corpo, sangue, alma e divindade. 2. Ato central do culto cristão; missa, banquete sagrado, comunhão, ceia do Senhor, memorial do Senhor, pão dos anjos, pão da alma: Celebrar a eucaristia (FERREIRA, 2004).

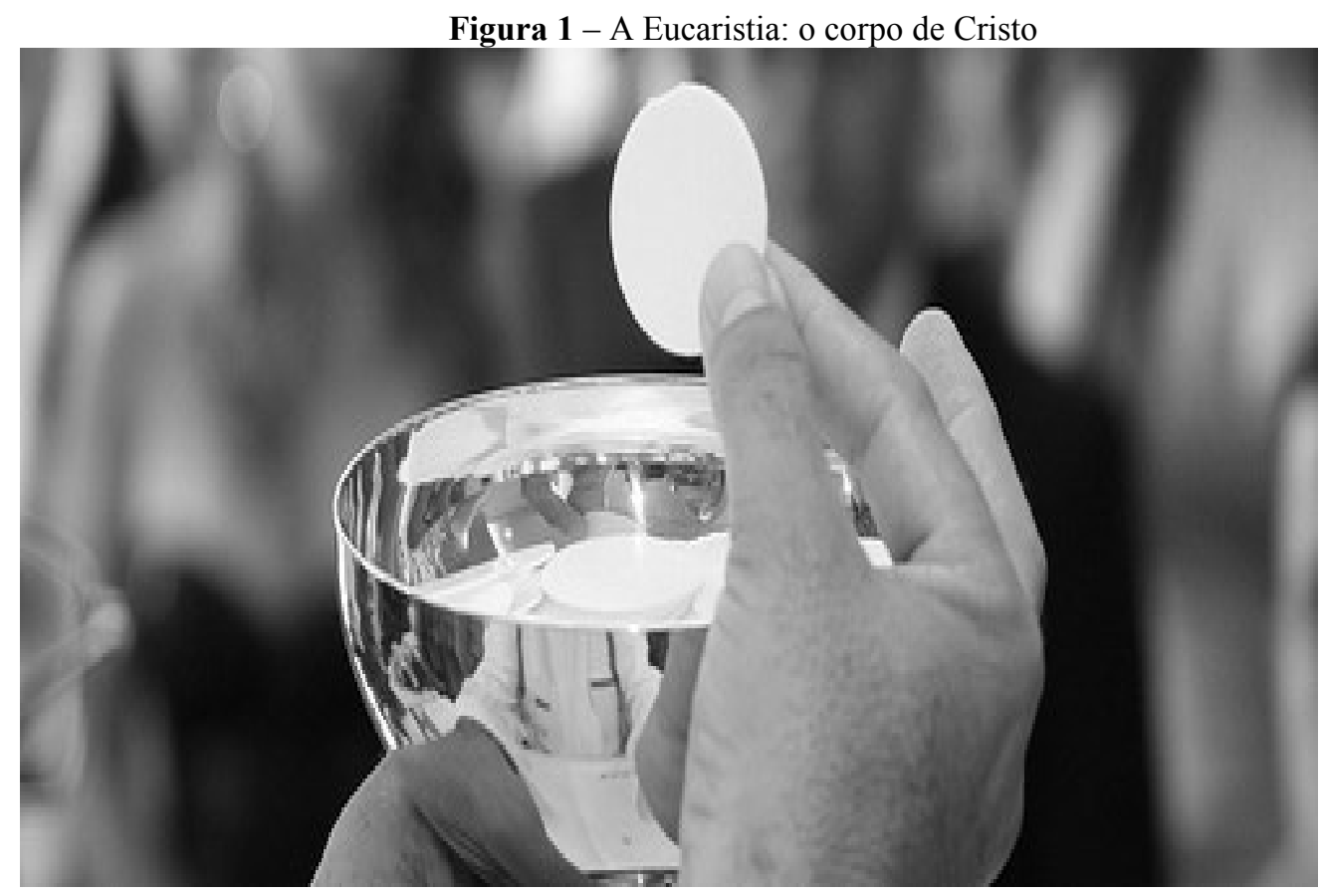

Fonte: Gonzaga, 2015

Assim, pela crença católica, a comunhão com Deus só se realizaria por meio da presença de Jesus Cristo. Jesus é a figura da porta ou do canal aberto de comunicação com Deus, conforme apresentado nos escritos bíblicos: "Eu sou a porta. Se alguém entrar por mim será salvo; tanto entrará como sairá e encontrará pastagem" (BÍBLIA, 1980, Evangelho de Jesus Cristo segundo São João, Capítulo 10, versículo 9) e "Ninguém vai ao Pai senão por mim." (BÍBLIA, 1980, Evangelho de Jesus Cristo segundo São João, Capítulo 14, versículo 6).

Adentrando ao contexto do Candomblé, este também realiza seu ritual comunicacional de comunhão. Conforme descrição de uma Mae de Santo, seu ritual de comunhão, que tem como ator central o Exu, é realizado em duas etapas sucessivas. Tais etapas são materializadas no padê de Exu e na iniciação do xirê: 
O primeiro ritual que acontece antecedendo a festa propriamente dita é o padê de Exu que pode ser feio à tarde ou seis horas antes de começar a gira dos Orixás. É necessário fazer este ritual porque se acredita que este Orixá é o principal mensageiro que abre os caminhos para a vinda dos outros. Dessa maneira pode-se prosseguir o xirê que é uma sequência de música para todos os Orixás cultuados na casa ou na nação. O xirê significa brincar, dançar com os Orixás, começando com Exu e indo até Oxalá (FERREIRA, 2006, p. 20).

O padê é a oferta de comunhão. É a oferenda realizada àquele que permite a comunicação com os outros Orixás, o Exu. Assim, pela crença do Candomblé, a comunhão com os Orixás só se realizaria por meio da presença de Exu.

Figura 2 - Oferenda de alimento do padê de Exu: Exu come primeiro

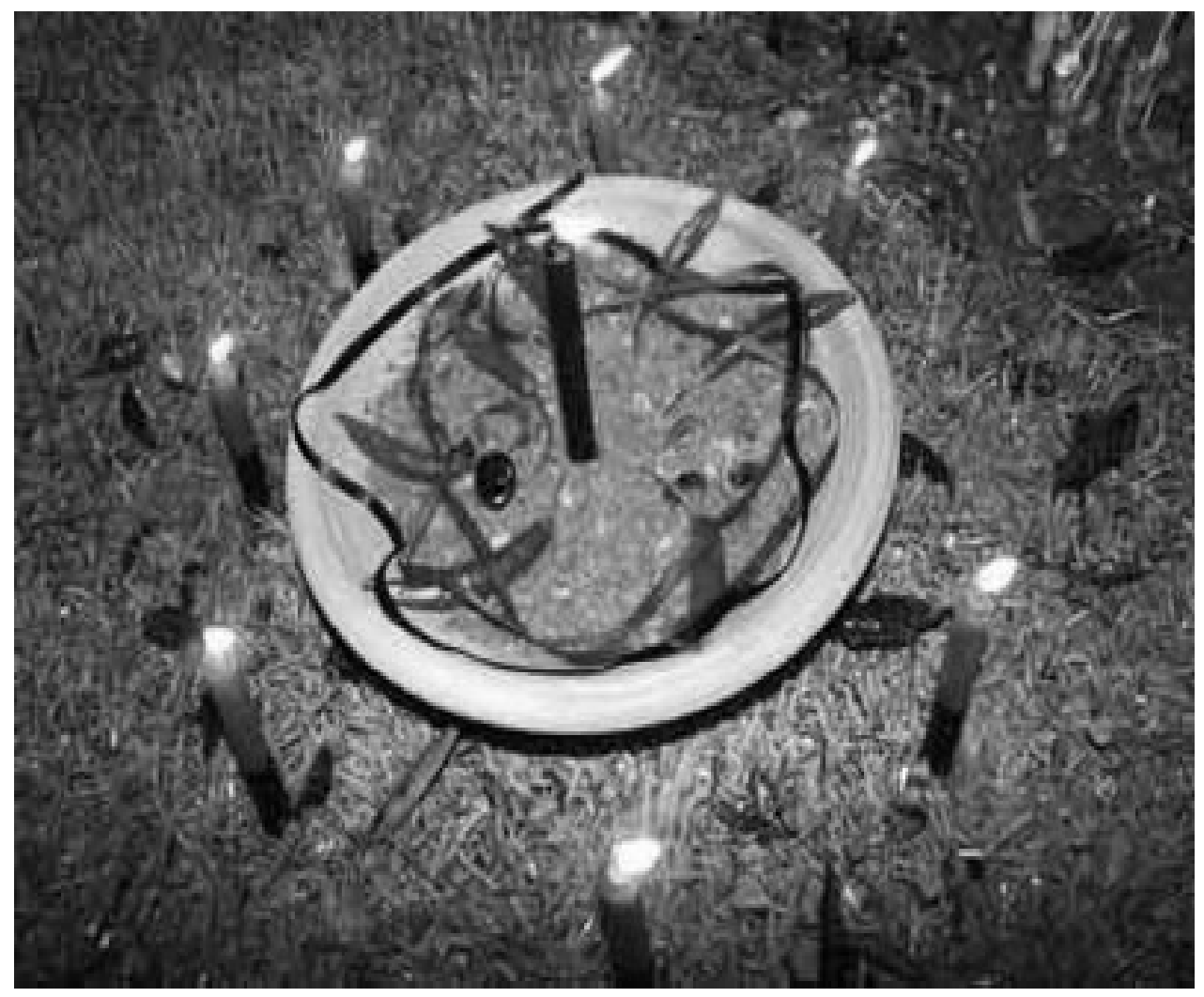

Fonte: CEPJA, 2015

A figura de Exu é a porta ou o canal aberto de comunicação com os Orixás. O rito de comunhão desta religião se inicia com o padê de Exu e termina com a iniciação do xirê pela evocação primeira de Exu, pois sem ele os Orixás não se apresentam e não se comunicam. Caso Exu não seja evocado primeiro "para propiciar sua delicada missão" (PRANDI, 2005, p. 182), ele atrapalhará o rito, desconectando a comunicação com o terreno superior. 
Figura 3 - Xirê no Candomblé

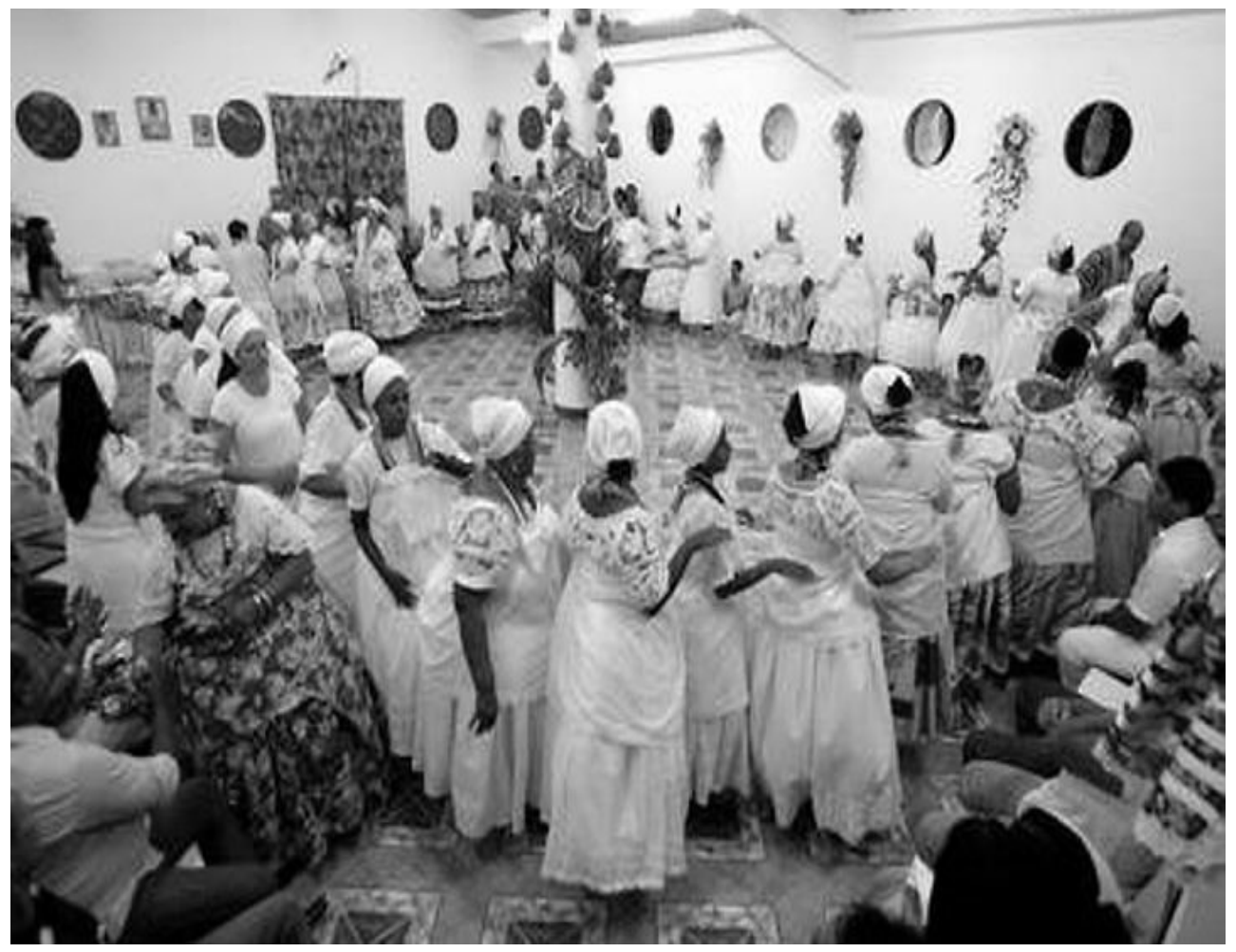

Fonte: Catraca Livre, 2015

No contexto desses ritos antropocomunicacionais de comunhão é que se apresenta a música como instrumento que promove a comunhão, e, ao mesmo tempo, é considerada instrumento de celebração, de comunicação, de instrução, de educação das crenças e tradições (FERREIRA, 2006).

Sobre a música no Catolicismo, Campos (1987, p. 41) traz sua compreensão na relação com a liturgia pautando-se no Diretório Litúrgico da Confederação Nacional dos Bispos do Brasil:

Graças ao canto [e à música instrumental], a oração se exprime com maior suavidade, mais claramente se manifesta o mistério da liturgia... mais profundamente se atinge a unidade dos corações pela unidade [do som dos instrumentos e] das vozes, mais facilmente se elevam as almas, pelo esplendor das coisas santas, até que as realidades supra terrenas, enfim, toda a celebração prefigura mais claramente aquela efetuada na Jerusalém celeste. (CAMPOS, 1987, p. 41)

Por isso, Ferreira (2006) acrescenta que é de suma importância a música litúrgica para o rito e a ação litúrgica celebrada. A música litúrgica tem a função de ligação ou comunicação do homem com Deus e com os seus iguais no credo, e ao mesmo tempo função profética, já que nessa música devem estar impressas as realidades de Deus e do homem.

Comun. \& Inf., Goiânia, GO, v. 19, n. 2, p. 04-18, jul./dez. 2016. 
A música no Candomblé tem funções similares à música no Catolicismo. A importância da música nesta outra base religiosa é exposta por Silva, Dacach e Lopes (2005, p. 14):

As cantigas [cantos e sons dos instrumentos] abrem as diversas capacitações. Nos rituais e obrigações iniciam-se com aquelas que trazem pedidos de licença para o início dos trabalhos de santo. São usadas para evocar a proteção dos deuses e deusas para que tudo aconteça de maneira satisfatória. Essa prática não pode ser desconsiderada nas capacitações [e experimentações dos fiéis], pois envolve e une as pessoas (SILVA; DACACH; LOPES, 2005, p. 14).

Prandi (2005, p. 183) reforça a importância da música nos ritos enfocando que os elementos do saber no contexto do candomblé "consiste no conhecimento e domínio do seu vastíssimo repertório musical. Poderíamos dizer que para cada gesto há no candomblé uma correspondente cantiga. Para tudo se canta".

No bojo destas reflexões algumas questões sociais são suscitadas: Qual a função e a importância da música nos ritos antropocomunicacionais de comunhão pertencentes ao Catolicismo e ao Candomblé? Como se dá a experiência do homem com o sagrado nesse contexto de comunhão através da música? A música comunica e forma, aliás, (in)forma, e de que forma?

Como possíveis respostas à estas questões, afirma-se que a música é a (in)formação necessária na experiência do homem com o sagrado nessas religiões quando dos ritos antropocomunicacionais de comunhão com os seres sobrenaturais adorados, respectivamente os Orixás e o Deus Javé em referência ao Candomblé e ao Catolicismo, respectivamente, por meio das personagens/entidades de ligação Exu e Jesus Cristo.

Pontua-se a necessidade de afastamento de qualquer preconceito na compreensão, com base no sincretismo religioso, da analogia trazida entre a figura católica de Jesus Cristo à figura do Orixá Oxalá do Candomblé. Exu é visto como personagem pejorativamente inferior e associado à antítese de Jesus Cristo e de seu pai, o Deus Javé.

Isto encontra explicação nas reflexões de Verger (1993) em que Exu detentor de caráter violento, grosseiro, vaidoso, divertido e indecente. Os primeiros missionários que chegaram ao Brasil e que tiveram contato com os escravos africanos e seus descendentes brasileiros o assimilaram ao diabo, erroneamente, dado seus propósitos de expansão e dominação religiosa, tornando-o símbolo de tudo o que é maldade, perversidade, objeção e ódio. 
Mas há quem não corrobore desta descrição de Exu, tanto que Bastide (1978) se referiu ao mesmo como incompreendido ou a "divindade caluniada", orixá que nunca mais se livrou da imputação do mal.

Destarte, chama-se a atenção para o estabelecimento de outro olhar sobre as personagens/entidades: a possível analogia contrastiva entre de Exu e Jesus, respeitando, obviamente, as suas singularidades, credos e contexto sócio religiosos, justamente pelas suas funções de agentes de comunhão, de comunicação, de canais da experiência do homem com o sagrado a partir da experiência primeira com eles mesmos.

Popularmente, a definição de sagrado se encontra na dicotomia entre sagrado versus profano. Contudo, as referências sociais e antropológicas vão mais além.

Para Otto (1985), o sagrado é composto pela tensa e contínua relação do racional e do não racional a partir da categoria denominada por ele de numinoso. O numinoso (do latim, numem = "deus"), designa todas as experiências do sagrado, pois elas são provocadas pela revelação do poder divino. O numinoso não se assemelha a nada de humano ou cósmico. Assim, o sagrado se manifesta sempre como realidade plenamente diferente das realidades naturais.

A partir da compreensão da experiência com o sagrado, o mysterium tremendum, segundo Otto (1985), apresenta-se diante do numinoso como temor ou tremer, ou o temor de Deus. Otto (1985, p. 31) cita santo Agostinho, quando diz: “Que luz é esta que me clareia e que me fere o meu coração sem ofender? Que me faz tremer e abrasar! Tremo, porque sou diferente dela, abraso-me enquanto com ela me pareço.” Não se pode assemelhar, portanto, o mysterium tremendum ao terror, medo, horror demoníaco. Este mistério faz tremer porque está ligado ao que é diferente ao "totalmente outro".

Eliade (1992, p. 20) considera o sagrado e o profano como "duas modalidades de ser no mundo, duas situações existenciais assumidas pelo homem ao longo de sua história". Sagrado e profano se referem às duas faces da existência humana. Para o autor, a experiência humana com o sagrado só acontece a partir da compreensão e processamento de informações sobre o momento em que o sagrado se manifesta ao homem, quando ocorre a hierofania.

A hierofania é uma palavra grega que significa "algo do sagrado se nos revela", que pode acontecer por meio de uma árvore, de uma nuvem, de uma pedra, ou ainda, na própria encarnação do sagrado como no cristianismo em que Deus se faz homem na pessoa de Jesus.

No contexto do termo religião, Eliade $(1989$, p. 9) faz uma ressalva com relação ao mesmo dizendo que esta é "bastante limitada" para explicar a experiência do homem com o sagrado, porquanto a experiência não precisa necessariamente estar vinculada à crença em

Comun. \& Inf., Goiânia, GO, v. 19, n. 2, p. 04-18, jul./dez. 2016. 
Deus, deuses ou fantasmas, já que esta relacionada às ideias de Ser, Sentido e Verdade. Por isso Eliade (1989, p. 10) define assim o sagrado:

O sagrado é um elemento da estrutura da consciência e não um estágio na história da consciência. Um mundo com sentido- e o homem não pode viver no $<<$ caos $>>$ - é o resultado de um processo dialético a que se pode chamar manifestação do Sagrado (ELIADE, 1989, p. 10).

Nesse sentido, para que a experiência do sagrado aconteça faz-se necessário a convicção de que é possível experimentar uma unidade perfeita, uma comunhão intrínseca com o sagrado vislumbrando uma nova percepção do universo. A manifestação do sagrado torna todas as dimensões da vida humana (trabalho, família, comunicação, sexualidade, alimentação) significativas, pois todas as dimensões do cotidiano se tornam sacralizadas (ELIADE, 1992).

\section{CONSIDERAÇÕES SOBRE A COMUNICAÇÃO DA MÚSICA SAGRADA}

A música sacra se refere à arte ou ciência de combinação/organização de sons agradáveis ao ouvido, concernente às coisas divinas, às religiões, e que não podem faltar nos ritos antropocomunicacionais e cultos religiosos (FERREIRA, 2006).

A música perpassa por vários ciclos e modos de ser, pensar e agir, modos de práticas informacionais e comunicacionais diversas, desde criação, comunicação (muitas vezes por oralidade, até pelo uso de mídias modernas), acesso e uso.

Para o povo africano a música não é apenas uma maneira de transmitir informações psicológicas, culturais, sentimentos e emoções, ela vai além deste conceito, pois a música e seu som são essenciais veículos de comunicação.

A música fornece um canal de comunicação entre o mundo dos vivos e dos espíritos e serve como meio didático para transmitir o conhecimento sobre o grupo étnico de uma geração para outra (PRANDI, 2005, p. 5).

Dessa forma, a música é comunicação e tem função fundamental nos rituais afrobrasileiros, pois atua como mantenedora e disseminadora dos ensinamentos sagrados, auxiliando na continuação da religiosidade de um povo, sendo também condutora do axé (força sagrada) que é a força vital do povo de santo.

A música de candomblé, que é música aclimatada no Brasil, é basicamente ritmo. Ritmos intensos produzidos por tambores que há muitos extravasaram os portões dos terreiros para invadir ruas e avenidas da cidade profana no carnaval e fora dele (PRANDI, 2005, p. 5).

Comun. \& Inf., Goiânia, GO, v. 19, n. 2, p. 04-18, jul./dez. 2016. 
No entanto, vale salientar que fazer distinção entre o sagrado e profano nas tradições afro-brasileiras deve ser algo prudente, já que na África o canto sempre foi associado a todas as circunstâncias da vida, não só como parte primordial nas reuniões das comunidades de fé, mas também como transmissora de valores sociais, políticos, econômicos e religiosos.

Nessa perspectiva, a música ultrapassa o momento da cerimônia religiosa ligando o ritual sagrado ao profano, transmitindo fortes sentimentos de acordo com o momento, sejam eles agradáveis ou difíceis, sendo a música o coração do candomblé, tanto nas festas públicas, quanto no dia-a-dia das pessoas que vivem nesta religiosidade, mãe, pai e filhas de santo.

Considerando a música no Cristianismo, especificamente na Igreja Católica, tem-se que esta assume um papel fundamental no sentido de (in)formação e comunicação por meio da catequese ou do ensino religioso, já que os temas abordados versam sobre a santidade de Deus, a vida de Jesus, o Espírito Santo, a Virgem Maria e a Igreja, como condutas morais codificadas e partilhadas pelos seus fieis.

Originalmente a música católica sofreu grande influência da música clássica grega. Os primeiros cristãos realizavam as celebrações com o canto em todas as partes da Missa, não existiam momentos recitados ou em segredo. Eram cantados também o Cânon e até as leituras com melodia recitativa. O canto gregoriano reduziu, na Idade Média, a participação do povo no âmbito da musica sacra, uma vez que esta se tornara o canto de grupos preparados e formados, elitistas e eruditos, clérigos e classistas (CAMPOS, 1987, p. 40).

Mesmo com todas as transformações sofridas pela música sacra do período medieval até os dias atuais, observa-se a Missa como um todo musical e como uma unidade temática, uma vez que as músicas são escolhidas para uma determinada celebração de acordo com o tempo litúrgico, que se divide em Tempo Comum, Tempo do Advento, Tempo do Natal, Tempo da Quaresma e Tempo Pascal. Cada tempo é constituído de uma característica específica a ser celebrada sobre a vida de Jesus (CAMPOS, 1987).

A importância da música para Igreja Católica é inegável. O papel da comunicação litúrgica através dos signos/símbolos religiosos é imprescindível. O antigo Papa João Paulo II, em 2003, por ocasião do Centenário do Documento Eclesiástico sobre a música sacra, instituído pelo Papa São Pio X, destacou a função da música como um patrimônio cultural de valor inestimável, sobressaindo-se dentre as diversas artes pelo fato de ser uma parte necessária e integral na liturgia, tendo o canto tarefa ministerial no serviço divino.

Já o Papa Emérito Bento XVI, afirmou que a música cria nas pessoas ressonâncias "que são como uma sintonização com a beleza e a verdade de Deus", acrescentando que, quando

Comun. \& Inf., Goiânia, GO, v. 19, n. 2, p. 04-18, jul./dez. 2016. 
escuta um minueto de Mozart, "parece que os anjos participavam com seus cantos". Para ele, especificamente a música sacra é um "patrimônio espiritual, artístico e cultural" que "é necessário conservar, manter vivo e divulgar" entre a comunidade eclesiástica (CANÇÃO NOVA, 2015).

Em outro momento, o Papa Bento XVI afirmou que a música sacra oferece "a experiência espiritual [...] ao transmitir a alegria de Deus". Dessa forma, ele publicizou que "a música contribua para aprofundar nossa relação com Deus, sirva para reavivar em nosso coração a alegria que brota da fé, para que cada um chegue a ser testemunha convencida em seu próprio ambiente cotidiano" (BANDA DIVINO DOM, 2009).

Em síntese, aí está o ponto nevrálgico da tensão comunicacional da (in)formação:

Como no mito de Orfeu a informação em seus momentos de passagem é cidadã de dois mundos com direção, mas carregando uma enorme tensão no ritual de passagem. Porém é nestes momentos de passagem que o fenômeno da informação apresenta sua característica mais bela, pois transcende ali a solidão fundamental do ser humano: o pensamento se faz informação e a informação se faz conhecimento (BARRETO, 2002, p. 58)

\section{CONSIDERAÇÕES FINAIS}

$\mathrm{O}$ artigo objetivou analisar o fenômeno sócio religioso como (in)formacional, com foco sobre a experiência do homem com o sagrado por meio da música nos ritos antropocomunicacionais de comunhão do Catolicismo e do Candomblé.

Assim, apresentou-se definição de música, enfocando sua presença em lugares e meios de comunicação no cotidiano dos indivíduos, incluindo sua presença em rituais de exaltação a determinadas entidades no âmbito das religiões.

Abordou-se a música no contexto do Catolicismo e do Candomblé como instrumento de celebração, de comunicação, de instrução, de educação de crenças e tradições religiosas. A música estabelece a ligação ou a comunicação do homem com a entidade do credo a que o mesmo se dedica.

Desta forma, concluiu-se que o conhecimento acerca da música nos espaços sagrados precisa ser amplamente investigado e compreendido, sobretudo no que se refere à utilização e funções da música na experiência religiosa e na interação do ser humano com a música.

Espera-se que as reflexões aqui expostas contribuam para desvelar alguns saberes religiosos que não são divulgados nos espaços sagrados.

Espera-se, ainda, que o estabelecimento do diálogo interdisciplinar a partir da Ciência da Informação e da Comunicação para com as Ciências das Religiões possa ser profícuo para o

Comun. \& Inf., Goiânia, GO, v. 19, n. 2, p. 04-18, jul./dez. 2016. 
debate sobre o tema explorado neste artigo, pois no diálogo com outros saberes, estas três ciências ainda ampliam os seus limites pela possibilidade de utilização de referências da Antropologia, da Sociologia, da Educação, das Artes, priorizando a música, além dos próprios saberes culturais religiosos, populares e pragmáticos, solicitados à compreensão do fenômeno aqui discutido.

Por fim, trazemos a representação prático-epistemológica do constructo do objeto deste artigo apresentado em sua última figura como campo de estudo a não se esgotar:

Figura 4 - Representação prático-epistemológica do constructo do objeto do artigo

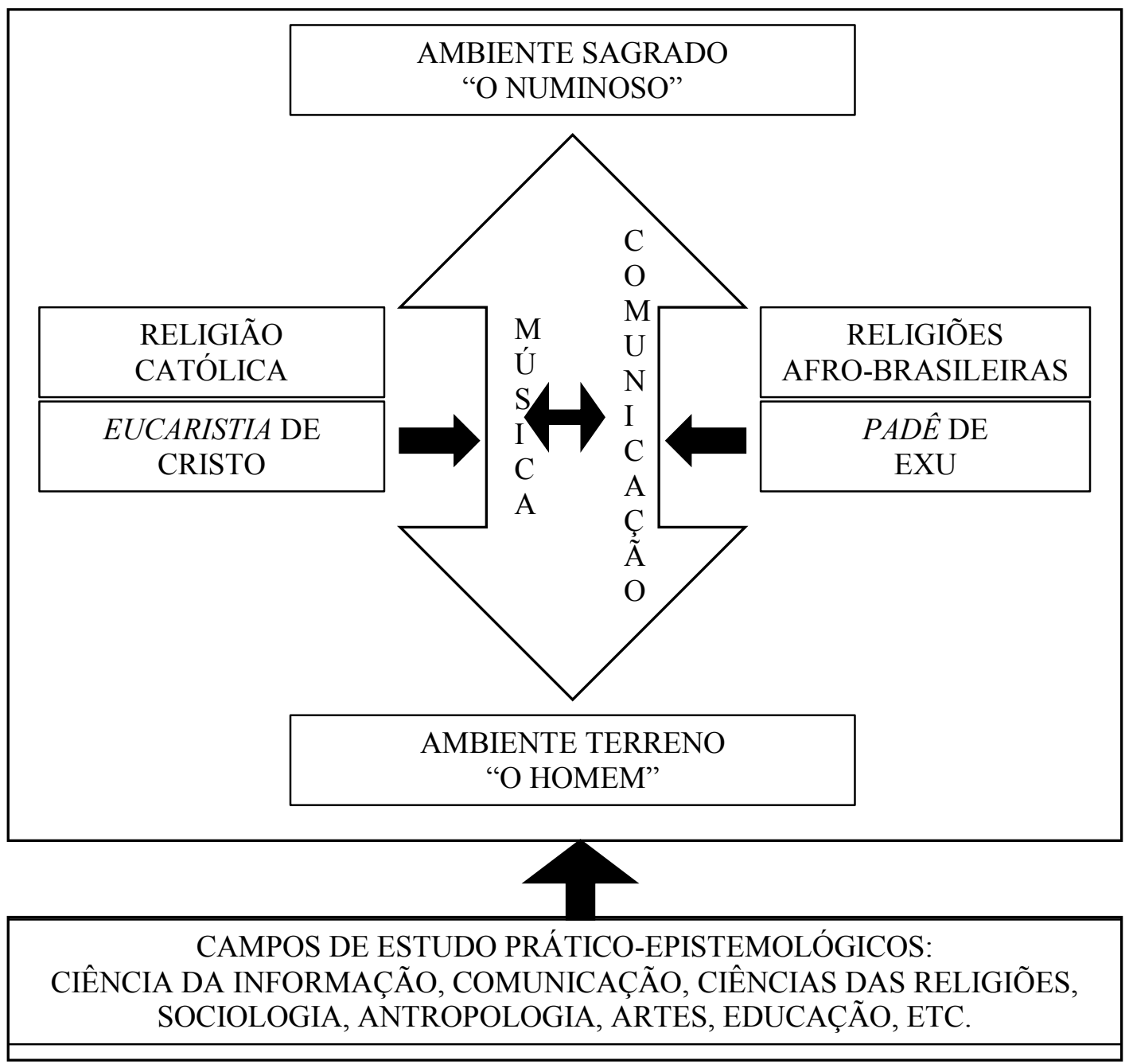

Fonte: Autores, 2015 


\section{REFERÊNCIAS}

BANDA DIVINO DOM. Papa Bento XVI fala sobre a música sacra. Disponível em: $<$ http://bandadivinodom.blogspot.com/2009/03/papa-bento-xvii-fala-sobre-musica-sacra.html>. Acesso em: 11 jul. 2009.

BARRETO, A. A. Transferência da informação para o conhecimento. In: AQUINO, M. A. (Org.). O campo da Ciência da Informação: gênese, conexões e especificidades. João Pessoa: Ed. Universitária/UFPB, 2002. p. 49-59.

BASTIDE, R. O Candomblé da Bahia. São Paulo: Companhia Editora Nacional, 1978.

BÍBLIA. Português. Bíblia Sagrada. Tradução de Padre Antônio Pereira de Figueredo. Rio de Janeiro: Encyclopaedia Britannica, 1980. Edição Ecumênica.

BRASIL. Lei $n^{0}$ 9.394, de 20 de dezembro de 1996. Estabelece as diretrizes e bases da educação nacional. Diário Oficial [da República Federativa do Brasil], Poder Legislativo, Brasília, DF, 23 dez. 1996. Disponível em: <http://www.planalto.gov.br/CCIVIL_03/leis/L9394.htm>. Acesso em: 20 jan. 2015.

CAMPOS, Pe. J. F. Liturgia: serviço do povo e para o povo de Deus. São Paulo: Paulinas, 1987.

CANÇÃO NOVA. Em $1^{\circ}$ discurso como Papa emérito, Bento XVI fala sobre música. 2015. Notícias Canção Nova, São Paulo, jul. 2015. Disponível em: <http://noticias.cancaonova.com/em-1o-discursocomo-papa-emerito-bento-xvi-fala-sobre-musica/>. Acesso em: 15 set. 2015.

CATRACA LIVRE. Casa das Rosas realiza Xirê para resgatar identidade negra. Foto: Jorge Alfredo. 2015. Disponível em: <http://pretajoianews.blogspot.com.br/2015/09/casa-das-rosas-realiza-xirepara.html>. Acesso em: 4 set. 2015.

CENTRO ESPÍRITA PAi JOÃo DE ANGOLA (CEPJA). Padê de Exu. 2015. Disponível em: $<$ http://centropaijoaodeangola.net/pade_de_exu_88.html $>$. Acesso em: 15 set. 2015.

COSTA, L. F.; RAMALHO, F. A. Religare: comportamento informacional à luz do modelo de Ellis. Transinformação, Campinas, v. 22, n. 2, p. 169-186, maio/ago. 2010.

ELIADE, M. Origens: história e sentido na religião. Lisboa: Edições 70, 1989.

ELIADE, M. O sagrado e o profano. São Paulo: Ed. Martins Fontes, 1992.

FERREIRA, A. B. H. Novo Dicionário Eletrônico Aurélio versão 5.0. São Paulo: Positivo, 2004.

FERREIRA, A. M. A música nos ritos católicos e afro-brasileiros: algumas comparações. 2006. 45f. Trabalho de Conclusão de Curso (Especialização em Ciências das Religiões) - Universidade Federal da Paraíba, João Pessoa, 2006.

GONZAGA, P. Sacramentos: a Igreja vive da Eucaristia. 2015. Disponível em:

$<$ http://www.a12.com/formacao/detalhes/sacramentos-a-igreja-vive-da-eucaristia $>$. Acesso em: 10 fev. 2015.

HUMMES, J. M. Por que é importante o ensino da música? Considerações sobre as funções da música na sociedade e na escola. Revista da ABEM, Porto Alegre, v. 11, p. 17-25, set. 2004.

Comun. \& Inf., Goiânia, GO, v. 19, n. 2, p. 04-18, jul./dez. 2016. 
LÔBO, R. M. F.; CHRISTIAN, M. M. B. A Música Religiosa Inserida nas Programações Radiofônicas. 2014. Disponível em:

$<$ http://www.portalintercom.org.br/anais/nordeste2014/resumos/R42-1264-1.pdf $>$. Acesso em: 28 dez. 2014.

MENDONÇA, J. S. A mensagem na música: estudos da Teomusicologia sobre os cânticos dos Adventistas do sétimo Dia. 2014. 290 f. Tese (Doutorado em Música) - Universidade Estadual Paulista Júlio de Mesquita Filho, São Paulo, 2014.

OLIVEIRA, Jetro Meira de. Rituais de equilíbrio e desenvolvimento: práticas musicais litúrgicas islâmicas, judaicas e cristãs. 2014. Disponível em:

$<$ http://www.unesp.br/portal\#!/noticia/10889/pesquisa-busca-mapear-relacao-entre-musica-ereligiao/>. Acesso em: 10 jan. 2014.

OTTO, R. O sagrado: um estudo do elemento não-racional na ideia do divino e a sua relação com o racional. São Bernardo do Campo: Imprensa Metodista, 1985.

PRANDI, R. Música sacra e música popular. In: PRANDI, R. Segredos guardados: orixás na alma brasileira. São Paulo: Companhia das Letras, 2005.

SILVA, J. M. da; DACACH, S.; LOPES, F. Atagbá: guia para promoção a promoção da saúde nos terreiros. Rio de Janeiro: Rede Nacional de Religiões Afro-Brasileiras e Saúde, 2005.

VERGER, P. F. Orixás: Deuses Iorubás na África e no Novo Mundo. São Paulo: Corrupio, 1993.

VIEIRA, A. M. B. J. Educação infantil e música: considerações na formação inicial de professores. 2012. 50 f. Trabalho de Conclusão de Curso (Graduação em Pedagogia)- Universidade Estadual de Londrina, Londrina, 2012.

Recebido em: 05/06/2015

Aceito em: 16/09/2015

Publicado em: 31/12/2016

Comun. \& Inf., Goiânia, GO, v. 19, n. 2, p. 04-18, jul./dez. 2016. 